\title{
Assessing Personality Features and Their Relations With Behavioral Problems in Adolescents: Tridimensional Personality Questionnaire and Junior Eysenck Personality Questionnaire
}

\author{
Po-Hsiu Kuo, Yi-Chien Chih, Wei-Tsuen Soong, Hao-Jan Yang, and Wei J. Chen
}

\begin{abstract}
This study examines the applicability for adolescents of the Tridimensional Personality Questionnaire (TPQ), which was originally designed for adults, as compared to the Junior Eysenck Personality Questionnaire (JEPQ). The study also evaluates their interrelationship and associations with various behavioral problems as reported by parents using the Child Behavior Checklist (CBCL). In a representative community sample of $\mathbf{9 0 5}$ adolescents, the results of internal consistency, test-retest reliability, and factor analysis showed that both the Harm Avoidance (HA) and the Novelty Seeking (NS) scales of the TPQ have sound construct validity, although the Reward Dependence
\end{abstract}

A SSESSMENT OF personality features in youths has become increasingly common, particularly in the investigation of relations between personality and various health behaviors. ${ }^{1}$ Twin studies have shown that there is strong evidence of genetic contribution to personality. ${ }^{2-4}$ Hence, the role of personality predisposition becomes very important in probing the complex etiology of behavioral problems during the rapid adolescent development. ${ }^{5}$ Previous studies among adults have strongly indicated that personality has a factor structure of cross-cultural validity, ${ }^{6,7}$ despite the debate over the number of factors needed. ${ }^{8-10}$ However, relatively few personality questionnaires have been developed for use in children and adolescents as compared with those for adults.

One commonly used personality questionnaire specifically designed for use in adolescents is

From the Institute of Epidemiology, College of Public Health and Department of Psychiatry, College of Medicine, National Taiwan University, Taipei; Department of Psychiatry, National Taiwan University Hospital, Taipei; and the Center for Disease Control, Department of Health Executive Yuan, Taipei, Taiwan.

Supported by grants from the National Science Council, Taiwan (NSC86-2314-B002-328, NSC87-2314-B002-290, NSC88-2314-B002-247, and NSC89-2320-B002-106).

Address reprint requests to Wei J. Chen, M.D., Sc.D., Institute of Epidemiology, College of Public Health, National Taiwan

University, 1 Jen-Ai Road, Sec. 1, Taipei 100, Taiwan.

(1) 2004 Elsevier Inc. All rights reserved.

0010-440X/04/4501-0011 \$30.00/0

doi:10.1016/j.comppsych.2003.09.011
(RD) scale has less so. The intercorrelation and factor analysis of the two questionnaires showed that the TPQ and the JEPO are not simply alternative descriptions of the same construct of personality. In their associations with various behavioral problems, the scales of the TPO are relatively more specifically associated with behavioral problems than the scales of the JEPO. Our results provide empirical support for the applicability of the NS and the HA scales of the TPO in adolescents, particularly in relation to behavioral problems.

(c) 2004 Elsevier Inc. All rights reserved.

the Junior Eysenck Personality Questionnaire (JEPQ), ${ }^{11}$ which consists of the Extraversion (E), Neuroticism (N), Psychoticism (P), and Lie (L) scales. The JEPQ has been widely used and in general has shown good cross-cultural reliability ${ }^{12}$ and acceptable validity. ${ }^{13-15}$ The JEPQ has been applied in various studies examining the relationship between personality traits and health behaviors, ${ }^{16,17}$ as well as adolescent behavioral problems, such as substance use, ${ }^{18}$ depressive symptoms and sleep disturbance, ${ }^{19}$ attitude towards truancy, ${ }^{20}$ bully/victim problems, ${ }^{21}$ and conduct disorder. ${ }^{22}$

Another notable approach toward measurement of personality is the biosocial theory of personality put forth by Cloninger, ${ }^{23}$ which is heuristically useful because it attempts to integrate information from epidemiological, psychometric, and neurobiological studies. The scale developed from this theory, the Tridimensional Personality Questionnaire (TPQ), consists of three genetically independent dimensions, i.e., Novelty Seeking (NS), Harm Avoidance (HA), and Reward Dependence (RD). Combinations of extreme deviations on the three dimensions are hypothesized to be associated with specific psychopathologies, such as personality disorders, ${ }^{24}$ depression, ${ }^{25}$ and substance use/ abuse. ${ }^{26-28}$ Many studies among adults have found that the TPQ has acceptable cross-culture reliability and validity, ${ }^{29-32}$ but the psychometric properties of the RD were not as sound as that of the NS and the HA. ${ }^{33,34}$ The utility of the TPQ is further 
demonstrated in its extensive use in the recent mapping for personality genes..$^{35,36}$ It is also noteworthy that the TPQ was originally designed for adults and does not have a version for children or adolescents. The few studies applying TPQ for children used ratings by their teachers, rather than as reported by children themselves. ${ }^{37}$ Thus, it is worth evaluating the psychometric properties of self-reported TPQ among adolescents. Furthermore, examining the relationship between the TPQ and the JEPQ may help to understand the underlying structure of personality in adolescents. Previous studies in adults have found that the two systems are not simply alternative descriptions of the same dimensions of personalities. $27,31,38,39$

Since the constructs of both the JEPQ and the TPQ indicate that each personality factor predicts certain types of behaviors as individuals grow, it is of interest to assess the relationship between the personality factor scores and behavioral problems in youths. For instance, the construct of psychoticism comprises aggressive, impulsive, and antisocial traits and the construct of extroversion indicates active or sensation-seeking traits. ${ }^{40}$ These personality features are hypothesized to be associated with more externalizing behavioral problems. In addition, the construct of neuroticism or emotional instability exhibits anxious, depressed, and moody traits and is hypothesized to be associated with more internalizing problems. ${ }^{40}$ In this aspect, the Child Behavior Checklist (CBCL), which is one of the most commonly used instruments of dimensional approach in assessing adolescent behavioral/emotional problems, can be a useful tool in assessing such relationship. However, there have been few studies that examined the relations between the behavioral problems assessed in the CBCL and personality features ${ }^{41,42}$ which were limited to clinical subjects and had small sample size.

In the present study we examined the psychometric properties of the TPQ and the JEPQ in a representative community sample of adolescents in Taiwan. Correlation and potential common factor structure between these two personality scales were also investigated. Moreover, we investigated the influences of personality traits on adolescent behavioral/emotional problems.

\section{METHOD}

\section{Participants}

The subjects in this study were 905 junior high school students ( 458 girls and 447 boys) in Taipei City. The sampling of the participants has been described in detail elsewhere. ${ }^{43,44}$ Briefly, we stratified the 73 public junior high schools in Taipei City in 1996 by educational levels of the residents into three groups, and selected randomly one school from each group. Then, three classes were randomly selected from each grade in each of the three selected schools. In total, there were 971 students eligible for this study. After informed written consent was obtained from the students and their parents, 905 (93\%) students completed the self-reported questionnaire inquiring about demographic characteristics and detailed individual features, including substance use, handedness, and personality characteristics. Of the 905 students, 854 (88\%) of their parents completed the CBCL for evaluating the behavioral problems of the children. The mean age of the participating students was 14.1 (SD 1.0) years, ranging from 12 to 17 years. The most common parental education level (the higher one in each family) was 12 years or more (43\%). No difference was found in the parental education level between boys and girls.

\section{Measurement Instruments}

In the present study, all students completed both the TPQ and the JEPQ along with the other questionnaires, and one of their parents completed the CBCL on them.

$J E P Q$. The JEPQ contains 81 "yes-no" self-report items, ${ }^{11}$ consisting of three higher order factors, i.e., E, N, and P. Following many other studies, ${ }^{45,46} \mathrm{~L}$, which was presumed to measure the "desirability response," was regarded as a fourth factor. The Chinese version of the JEPQ was prepared via two-stage translation. Before implementing the questionnaire, we held a pretest to evaluate if it was suitable for applying to adolescents in Taiwan. The results of the pretest indicated that adolescents could answer these questions without apparent difficulty.

TPQ. The TPQ is a 100-item self-administered true-false instrument that consists of three high-grade dimensions, i.e., NS, HA, and RD, each with four subscales. ${ }^{23}$ According to Cloninger's preliminary analyses, ${ }^{30}$ items 61 and 71 were dropped from the scoring because of their low factor loading, and hence the total scores of the TPQ ranged from 0 to 98 . The Chinese version of TPQ was prepared via two-stage translation. ${ }^{47}$ In this study we changed the examples provided at the end of three items (items 29, 47, and 51) to better suit adolescents' experience in Taiwan. The results of a pretest indicated that adolescents could answer these questions also without obvious difficulty.

$C B C L$. The CBCL/4-18 consists of 20 competence items and 118 items to assess behavioral/emotional problems. ${ }^{48}$ The items of behavioral/emotional problems are scored on a 3-point scale ( 0 if not true, 1 if somewhat true or sometimes true, and 2 if very true or often true). Eight narrow-band behavioral syndromes and three broadband behavioral syndromes were defined according to Achenbach. ${ }^{48}$ The broadband syndromes include Internalizing Problems (sum of Withdrawn, Somatic Complaints, and Anxious/Depressed), Externalizing Problems (sum of Delinquent Behavior and Aggressive Behavior), and 
Table 1. TPQ and JEPQ: Scale Means, Standard Deviations, Cronbach's Alphas, and One-Month Test-Retest Intraclass Correlations $(\boldsymbol{r})$

\begin{tabular}{|c|c|c|c|c|c|c|c|c|c|c|c|c|c|}
\hline \multirow[b]{2}{*}{ Scale } & \multirow[b]{2}{*}{ Items } & \multicolumn{4}{|c|}{ Boys $(N=446)$} & \multicolumn{4}{|c|}{ Girls (N = 459) } & \multicolumn{4}{|c|}{ Total $(N=905)$} \\
\hline & & Mean & SD & $\alpha$ & $r$ & Mean & SD & $\alpha$ & $r$ & Mean & SD & $\alpha$ & $r$ \\
\hline \multicolumn{14}{|l|}{ TPQ } \\
\hline NS & 34 & 17.6 & 4.1 & 0.56 & 0.52 & 18.1 & 4.6 & 0.67 & 0.76 & 17.8 & 4.4 & 0.62 & 0.65 \\
\hline$H A^{*}$ & 34 & 15.6 & 5.7 & 0.79 & 0.72 & 16.9 & 6.4 & 0.84 & 0.80 & 16.3 & 6.1 & 0.82 & 0.77 \\
\hline $\mathrm{RD}^{*}$ & 30 & 17.3 & 3.6 & 0.53 & 0.73 & 18.6 & 3.6 & 0.58 & 0.42 & 17.9 & 3.7 & 0.57 & 0.58 \\
\hline \multicolumn{14}{|l|}{ JEPQ } \\
\hline E & 24 & 15.7 & 4.3 & 0.79 & 0.78 & 15.5 & 4.6 & 0.81 & 0.90 & 15.6 & 4.4 & 0.80 & 0.85 \\
\hline $\mathrm{N} \dagger$ & 20 & 9.4 & 4.5 & 0.82 & 0.85 & 10.6 & 4.4 & 0.81 & 0.82 & 10.0 & 4.5 & 0.82 & 0.84 \\
\hline $\mathrm{P}+$ & 17 & 3.0 & 2.5 & 0.69 & 0.66 & 2.1 & 2.0 & 0.63 & 0.74 & 2.6 & 2.3 & 0.68 & 0.70 \\
\hline L† & 20 & 8.8 & 3.6 & 0.71 & 0.65 & 9.6 & 3.7 & 0.73 & 0.83 & 9.2 & 3.7 & 0.72 & 0.74 \\
\hline
\end{tabular}

NOTE. Number of students participated in test-retest was 90 for the TPQ and 83 for the JEPQ.

*Sex difference, $t$ test with Bonferroni correction, $P \leq .05 / 3=.017$ for the TPQ.

†Sex difference, $t$ test with Bonferroni correction, $P \leq .05 / 4=.013$ for the JEPQ.

Total Problems (all eight narrow-band syndromes' scores summed together).

The Chinese version of the CBCL, CBCL-C, was prepared via two-stage translation. ${ }^{44}$ The parents or guardians completed the CBCL-Cs at home, according to the status of the participating students in the preceding 6 months. The applicability of the CBCL-C in assessing the competence and behavioral/emotional problems in Taiwanese adolescents has been demonstrated. ${ }^{44}$ Briefly, the internal consistency and 1-month testretest reliability of the CBCL-C (all $\alpha$ 's and reliabilities $>0.60$ except for Thought Problems) were satisfactory. In addition, both exploratory and confirmatory factor analysis provided some support for the validity of Achenbach's cross-informant model in the Taiwanese adolescents.

\section{Statistical Analysis}

The scale means, distributions, and internal reliability were calculated for the TPQ and the JEPQ. The Pearson correlations between the scales of the TPQ and the JEPQ were also computed. For each scale, potential gender differences and age effects were examined using Student's $t$ test and univariate linear regression, respectively. In assessing age effect, we used each student's school grade (grade 7 to 9) instead of chronological age because some ages were rare (3\% aged 12 and $1 \%$ aged 17). In addition, we employed multiple linear regressions to evaluate the effect of age (i.e., grade in this study), sex, and interaction term of age and sex on each scale of the TPQ and the JEPQ, respectively. For evaluating effects of personality traits on behavioral problems, the score on each dimensional behavioral/emotional syndrome was regressed on all the scales of either the TPQ or the JEPQ with sex and parental education level as covariates in the multiple linear regressions. We adjusted for the effect of sex and parental education level in these multiple regression analyses because sex and parental educational level were found to be associated with some behavioral problems. Significance tests were conducted with Bonferoni's correction for multiple comparisons.

We employed both exploratory factor analysis (EFA) and confirmatory factor analysis (CFA) to evaluate the factor structure of the TPQ and the JEPQ. To be comparable with the results of previous EFA studies, principal component analysis with promax rotation was used for the $\mathrm{TPQ}^{30}$ and principal component analysis with varimax rotation was used for the $\mathrm{JEPQ}^{15}$ in this study. For the EFA of the TPQ, twelve subscales instead of individual items were subjected to analysis to increase statistical stability. ${ }^{47}$ Meanwhile, all the 81 items of the JEPQ were subjected to EFA since it does not have subscales. For the CFA, we used unweighted least-squares method to estimate the factor loadings. Three indices, goodness-of-fit index (GFI), adjusted GFI (AGFI), and root of the mean square residual (RMR), were chosen to assess the fit of each model. In general, a GFI value greater than 0.9 , a GFI value greater than 0.8 , and a RMR value less than 0.1 usually indicate a good fit. ${ }^{49}$ All statistical analyses were performed using the computer package program SAS. ${ }^{50}$

\section{RESULTS}

\section{Distribution and Reliability}

The distributions of the scales of both the TPQ and JEPQ were approximately normal, as indicated by the values of skewness and kurtosis, which fell within the range of -0.87 to 0.83 for each scale of the TPQ and the E, N, and L scales of the JEPQ. The only exception was the P scale of the JEPQ, in which skewness was 1.20 and kurtosis was 1.67 .

Results of descriptive statistics and reliability of the TPQ and JEPQ are shown in Table 1. Comparing the mean score of each scale between boys and girls, girls had higher scores on the HA and RD of the TPQ, and the N and L of the JEPQ. Meanwhile, boys scored higher than girls on the $\mathrm{P}$ of the JEPQ. All the differences remained significant after correction for multiple comparisons $(P \leq 0.05 / 3=$ .017 for the TPQ and $P \leq 0.05 / 4=.013$ for the JEPQ). The effect of age also reached a statistical significance, with ninth grade students having the highest scores on both the NS and the N, but the 
Table 2. Cronbach's Alphas $(\alpha)$ of TPQ Subscales and Factor Loadings of TPO From the Principal Component Analysis With Promax Rotation (N = 905)

\begin{tabular}{|c|c|c|c|c|c|c|}
\hline \multirow[b]{2}{*}{ Subscales } & \multirow[b]{2}{*}{ Items } & \multirow[b]{2}{*}{$\alpha$} & \multicolumn{3}{|c|}{ Factor } & \multirow[b]{2}{*}{$h^{2}$} \\
\hline & & & 1 & II & III & \\
\hline \multicolumn{7}{|l|}{ Novelty Seeking } \\
\hline NS1 (Exploratory Excitability) & 9 & 0.28 & -0.37 & 0.39 & & 0.40 \\
\hline NS2 (Impulsiveness) & 8 & 0.53 & & 0.72 & & 0.53 \\
\hline NS3 (Extravagance) & 7 & 0.56 & & 0.62 & & 0.41 \\
\hline NS4 (Disorderliness) & 10 & 0.25 & & 0.48 & 0.61 & 0.60 \\
\hline \multicolumn{7}{|l|}{ Harm Avoidance } \\
\hline HA1 (Anticipatory Worry) & 10 & 0.61 & 0.75 & & & 0.59 \\
\hline HA2 (Fear of Uncertainty) & 7 & 0.63 & 0.76 & & & 0.59 \\
\hline HA3 (Shyness With Strangers) & 7 & 0.65 & 0.76 & & & 0.62 \\
\hline HA4 (Fatigability) & 10 & 0.65 & 0.64 & & & 0.39 \\
\hline \multicolumn{7}{|l|}{ Reward Dependence } \\
\hline RD1 (Sentimentality) & 5 & 0.57 & & -0.31 & 0.81 & 0.71 \\
\hline RD2 (Persistence) & 9 & 0.34 & & -0.67 & & 0.46 \\
\hline RD3 (Attachment) & 11 & 0.60 & & & 0.55 & 0.37 \\
\hline RD4 (Dependence) & 5 & 0.36 & & & -0.31 & 0.11 \\
\hline Percentage of total variance & & & 22.5 & 15.5 & 10.4 & \\
\hline
\end{tabular}

NOTE. Only loadings with absolute values $>0.3$ are shown.

lowest scores on the $\mathrm{L}$ scale. In addition, there was no significant interaction between age and sex. Internal consistency of each scale was entirely within acceptable range (0.53 to 0.84$)$, although the alpha coefficients of the JEPQ scales were relatively slightly higher than those of the TPQ. To evaluate the test-retest reliability, the TPQ and the JEPQ were administered again 1 month later to 90 and 83 randomly selected students, respectively. According to the criteria of Fleiss, ${ }^{51}$ about half of the scales' intraclass correlation reliabilities were in the range of fair to good $(0.4$ to 0.75$)$ and the other half in the range of excellent $(>0.75)$ for both boys and girls.

\section{Factor Analysis}

Since the JEPQ is a commonly used instrument for youths in many countries, we report here only the major results of its factor analysis. For the EFA, four factors were derived from varimax rotation with $22.7 \%$ of the variance explained, which was similar to the percentage of the variance explained in a four-factor model $(22.2 \%)$ in a recent study in Hong Kong. ${ }^{9}$ Examining the factor loading of each item, only seven items were not allocated to the designated factors. The results of CFA for the fourfactor model of the JEPQ showed that GFI $=0.85$, $\mathrm{AGFI}=0.84$, and RMR $=0.01$. Although the value of GFI was slightly below 0.9 , the other two indices met the criteria of a good fit.
For the EFA of the TPQ, the standardized factor loadings following promax rotation are shown in Table 2. Because the factor structures in boys and girls were similar, only the results of total sample are reported. Although there were four factors with an eigenvalue greater than 1 (corresponding eigenvalues were $2.69,1.88,1.23$, and 1.21 ), a threefactor model was chosen on the basis of scree plot. In the three-factor solution, the model explained $48.4 \%$ of the variance. The first factor loaded highly positively on all HA subscales and negatively on the NS1 (Exploratory excitability) subscale, whereas the second factor loaded positively on all NS subscales and negatively on RD1 (Sentimentality) and RD2 (Persistence). The third factor loaded primarily on RD subscales (except RD2, Persistence) as well as NS4 (Disorderliness). On the basis of communality $\left(h^{2}\right)$, RD4 was not sufficiently saturated by any of the three factors.

In terms of CFA, we evaluated the three-factor model of the TPQ as originally specified. The goodness-of-fit indices showed that GFI $=0.94$, $\mathrm{AGFI}=0.91$, and RMR $=0.28$. Both the GFI and AFGI indicated a good fit of the model, but the large value of RMR suggested that some subscales might be poorly fit. If a four-factor model was adopted, in which RD2 was separated from the RD as an independent Persistence factor, ${ }^{52}$ the goodness-of-fit indices (GFI $=0.95$, AGFI $=0.92$, and $\mathrm{RMR}=0.26)$ were similar to that of the three- 
Table 3. Correlations Among TPQ and JEPO Scales ( $N=905)$

\begin{tabular}{|c|c|c|c|c|c|c|}
\hline & NS & HA & RD & $E$ & $\mathrm{~N}$ & $\mathrm{P}$ \\
\hline HA & $-0.15^{*}$ & & & & & \\
\hline $\mathrm{RD}$ & -0.08 & $-0.19 *$ & & & & \\
\hline$E$ & $0.26^{*}$ & $-0.52^{*}$ & $0.33^{*}$ & & & \\
\hline $\mathrm{N}$ & $0.14^{*}$ & $0.41 *$ & -0.02 & -0.07 & & \\
\hline$P$ & $0.34^{*}$ & -0.04 & $-0.21^{*}$ & $0.21 *$ & $0.24^{*}$ & \\
\hline $\mathrm{L}$ & $-0.44^{*}$ & -0.05 & $0.15^{*}$ & -0.06 & $-0.23^{*}$ & $-0.37^{*}$ \\
\hline
\end{tabular}

factor model. Because the EFA did not indicate that RD2 was a separate factor and the RMR of the four-factor model remained large, a three-factor model for the TPQ was used for the following analyses.

\section{Relationship Between the TPQ and the JEPQ}

Pearson correlations between scales both within and between questionnaires are displayed in Table 3. Because the correlations among boys and girls were very similar, only the results of total sample are reported. For the scales within the TPQ, all the pairwise correlations were mildly negative (all $<$ 0.2 ). For the scales within the JEPQ, the $\mathrm{L}$ was negatively correlated with the $\mathrm{E}$, the $\mathrm{N}$, and the $\mathrm{P}$. Meanwhile, the $\mathrm{P}$ was positively correlated with the $\mathrm{E}$ and the $\mathrm{N}$, and the $\mathrm{N}$ was negatively correlated with the $\mathrm{E}$. In terms of the interscale cross-instrument correlations, we found that some correlations were stronger than those within questionnaire, e.g., between the $\mathrm{E}$ and the HA, between the $\mathrm{L}$ and the NS, and between the N and the HA. It indicated that beyond the independent personality structure within each personality questionnaire, there might be some overlap between different personality questionnaires. However, these correlations were at most around 0.5.

The potential factor structure underlying the scales of the TPQ and the JEPQ together is presented in Table 4. The best three-factor solution accounted for $71 \%$ of the total sample variance. The NS and the HA of the TPQ could be unambiguously assigned to different factors, while the RD loaded on both factor III and I. For the JEPQ, the loading was clear for the $\mathrm{N}$, the $\mathrm{P}$ and the $\mathrm{L}$, although both the $\mathrm{P}$ and the $\mathrm{L}$ loaded on the first factor. Meanwhile, the E had loadings on both factor III and II.

\section{Personality Features and Behavioral Problems}

The regression coefficient estimates of each personality scale for various behavioral syndromes are presented in Table 5. For the TPQ, only the NS and the HA were significantly associated with adolescent behavioral problems. The HA was associated with all the internalizing behavioral problems except for Somatic Complaints, whereas the NS was associated with all the externalizing behavioral problems (Delinquent Behavior, Aggressive Behavior, and Externalizing Broadband Syndrome), and Thought Problems and Attention Problems. For the JEPQ, the pattern was not as clear as that of the TPQ, with more than one scale being associated with the same behavioral problem. The $\mathrm{N}$ scale was associated with all the internalizing behavioral problems, while the $\mathrm{P}$ scale was associated with all the externalizing behavioral problems. In addition, the $\mathrm{N}$ scale was also associated with Thought Problems, Attention Problems, and Externalizing Broadband Syndrome, and the P scale also associated with Social Problems and Attention Problems. The E scale was negatively associated with Withdrawn and Social Problems, and the L scale was negatively associated with Delinquent Behavior.

\section{DISCUSSION}

As far as we are aware, this is the first study to examine the applicability for adolescents of the TPQ, which was originally designed for adults, and compare it to that of the JEPQ. We attempted to investigate the two questionnaires' psychometric

\begin{tabular}{|c|c|c|c|c|}
\hline \multirow[b]{2}{*}{ Scale } & \multicolumn{3}{|c|}{ Factor Loading } & \multirow[b]{2}{*}{$h^{2}$} \\
\hline & 1 & II & III & \\
\hline \multicolumn{5}{|l|}{ TPQ } \\
\hline NS & 0.76 & & & 0.60 \\
\hline $\mathrm{HA}$ & & 0.77 & & 0.80 \\
\hline $\mathrm{RD}$ & -0.33 & & 0.92 & 0.83 \\
\hline \multicolumn{5}{|l|}{ JEPQ } \\
\hline $\mathrm{E}$ & & -0.31 & 0.65 & 0.76 \\
\hline $\mathrm{N}$ & & 0.87 & & 0.81 \\
\hline $\mathrm{P}$ & 0.76 & & & 0.57 \\
\hline $\mathrm{L}$ & -0.75 & & & 0.58 \\
\hline Percentage of total variance & 29 & 26 & 16 & \\
\hline
\end{tabular}

NOTE. Only loadings with absolute values $>0.3$ are shown. 
Table 5. Regression Coefficient Estimates for the Multiple Regressions of Scores for Individual Behavioral/Emotional Syndromes on Personality Features, With Adjustment for Sex and Parental Education Level

\begin{tabular}{|c|c|c|c|c|c|c|c|c|c|c|c|}
\hline \multirow[b]{2}{*}{$\begin{array}{l}\text { Personality } \\
\text { Scales }\end{array}$} & \multicolumn{4}{|c|}{ Internalizing } & \multirow[b]{2}{*}{$\begin{array}{l}\text { Social } \\
\text { Problems }\end{array}$} & \multirow[b]{2}{*}{$\begin{array}{l}\text { Thought } \\
\text { Problems }\end{array}$} & \multirow[b]{2}{*}{$\begin{array}{l}\text { Attention } \\
\text { Problems }\end{array}$} & \multicolumn{3}{|c|}{ Externalizing } & \multirow[b]{2}{*}{$\begin{array}{l}\text { Total } \\
\text { Problems }\end{array}$} \\
\hline & Withdrawn & $\begin{array}{c}\text { Somatic } \\
\text { Complaints }\end{array}$ & $\begin{array}{l}\text { Anxious/ } \\
\text { Depressed }\end{array}$ & $\begin{array}{l}\text { Broadband } \\
\text { Syndrome }\end{array}$ & & & & $\begin{array}{l}\text { Delinquent } \\
\text { Behavior }\end{array}$ & $\begin{array}{c}\text { Aggressive } \\
\text { Behavior }\end{array}$ & $\begin{array}{l}\text { Broadband } \\
\text { Syndrome }\end{array}$ & \\
\hline \multicolumn{12}{|l|}{ TPQ } \\
\hline NS & 0.10 & 0.22 & 0.15 & 0.18 & 0.18 & $0.32 *$ & $0.49 *$ & $0.53 *$ & $0.44^{*}$ & $0.50 *$ & $0.36^{*}$ \\
\hline $\mathrm{HA}$ & $0.29 *$ & 0.16 & $0.33^{*}$ & $0.33^{*}$ & 0.17 & 0.13 & 0.18 & 0.02 & 0.05 & 0.04 & $0.19 *$ \\
\hline $\mathrm{RD}$ & -0.26 & 0.14 & 0.01 & -0.04 & -0.27 & -0.17 & -0.17 & -0.14 & -0.05 & -0.08 & -0.11 \\
\hline \multicolumn{12}{|l|}{ JEPQ } \\
\hline $\mathrm{E}$ & $-0.31 \dagger$ & 0.14 & -0.13 & -0.14 & $-0.26 \dagger$ & -0.03 & -0.05 & 0.22 & 0.17 & 0.20 & -0.02 \\
\hline $\mathrm{N}$ & $0.43+$ & $0.41+$ & $0.54 \dagger$ & $0.57 \dagger$ & 0.24 & $0.30 \dagger$ & $0.31+$ & 0.25 & 0.24 & $0.26 \dagger$ & $0.39 \dagger$ \\
\hline$P$ & 0.005 & 0.19 & 0.16 & 0.15 & $0.68 \dagger$ & 0.38 & $0.65 \dagger$ & $0.71 \dagger$ & $0.92 \dagger$ & $0.91 \dagger$ & $0.57 \dagger$ \\
\hline $\mathrm{L}$ & -0.04 & -0.05 & 0.12 & 0.03 & 0.25 & -0.17 & -0.05 & $-0.32 \dagger$ & -0.24 & -0.28 & -0.07 \\
\hline
\end{tabular}

*With Bonferroni correction, $P \leq .05 / 33=.0015$ for the TPQ.

tWith Bonferroni correction, $P \leq .05 / 44=.0011$ for the JEPQ.

properties, inter-relationships, and associations with various behavioral problems. The results are discussed below.

The internal consistencies of the JEPQ scales in this study are equivalent or better than the mean alphas $(0.73$ for the E, 0.78 for the N, 0.68 for the $\mathrm{P}$, and 0.77 for the L) estimated from 23 studies of the JEPQ in various countries. ${ }^{12}$ Our study further showed that each JEPQ scale has a 1-month testretest reliability of magnitude similar to its internal consistency. The results of the EFA and the CFA indicated that the JEPQ has a factor structure as designated. This is consistent with many previous studies showing that the JEPQ has cross-cultural validity. ${ }^{13,14,53}$ Moreover, the effects of demographic features on the JEPQ scores are also as expected. Girls reported higher scores than boys on the $\mathrm{N}$ and the $\mathrm{L}$, and lower scores on the $\mathrm{P}$ and the E. In addition, the scales' distributions were crossculturally similar on the E and the N, as in Zimbabwean, Singaporian, and British children. ${ }^{14,53}$ Nevertheless, both the $\mathrm{P}$ and the L have relatively large differences in scales' mean and standard deviation in various countries. A cautionary note is that the percentage of the variance explained by the four-factor structure of the JEPQ is only $22.7 \%$, lower than that of the three-factor structure of the TPQ $(48.4 \%)$. However, the way of factor analysis was quite different between these two scales. For the JEPQ, all 81 original items were subjected to factor analysis, while for the TPQ items were pooled into 12 subscales and then subjected to factor analysis. This difference renders the results not directly comparable. Taken together, the JEPQ has good psychometric properties and is suitable for use in Taiwanese adolescents, provided local normative data are available.

The situation for the TPQ is slightly different. Although it was not specifically designed for use in youths, the questions themselves are readily applicable to youths if the examples in some items are modified, as we did in this study. Although the internal consistency of the three scales of the TPQ in boys and girls was slightly lower than those of Taiwanese adults (0.54 to 0.89$),{ }^{47}$ Czech (0.62 to $0.87),{ }^{31}$ or US $(0.58 \text { to } 0.85)^{38}$ population, the values were in acceptable ranges (0.53 to 0.84$)$. Of note is that an old version of the 100-item TPQ was used in the Czech study ${ }^{31}$ and a short-form of 54-item TPQ was used in the US study. ${ }^{38}$ In addition, the low alphas $(<0.6)$ in some subscales, especially the NS1 (Exploratory Excitability), the NS4 (Disorderliness), the RD2 (Persistence) and the RD4 (Dependence), are similar to those that have been reported for adults of various countries. ${ }^{30,54}$ The small number of items in each subscale may account for the low alpha values of all the subscales in general but not the particular ones with low values. The low internal consistency might have resulted in that the NS1 (Exploratory excitability), NS4 (Disorderliness), and the RD2 (Persistence) had considerable loading on nondesignated factor in the EFA. Many previous studies in adults of different countries, e.g., England, Yugoslavia, and the United States, have also found unstable factor loadings for the NS1 and the RD2, in which the loadings on the designated factor were low. ${ }^{30,34}$ The results of the CFA for the TPQ in this study are consistent with those of the EFA, in that some subscales might be poorly fit. 
Several predictions made on the basis of Cloninger's biosocial theory of personality were tested in this study to further examine the construct validity of the TPQ in youths. First, it is predicted that females have lower NS scores but higher HA and RD scores than males, as corroborated in Cloninger et al. ${ }^{30}$ We also found that adolescent girls have higher scores on the HA and the RD than boys. But contrary to our original expectations, girls scored slightly higher than boys on the NS in this study, though not reaching statistical significance. The same pattern of gender effect in the NS was found in Taiwanese adults. ${ }^{47}$ Many other studies in adults have found gender differences in the HA and the RD, but not in the NS. ${ }^{31,32,34,55,56}$ One study even reported that females had higher NS scores than males. ${ }^{57}$ On the basis of these studies, it seems that the gender difference in the HA and the RD is more culturally independent, while the NS is not. Second, it is predicted that as people grow older, their scores become lower in the NS and the RD and higher in the HA. Contrary to the expectation, we found that scores for the NS increased with grade in the limited age range of adolescents in this study.

Overall, our results indicate that both the HA and the NS of the TPQ have acceptable construct validity in adolescents as in adults. Nevertheless, the construct of RD is less robust in adolescents as in adults. ${ }^{47}$ Thus, the application of RD may be limited. It is noteworthy that there are wide variations in the mean and standard deviation of the TPQ scales in adults of similar age range in various countries. ${ }^{30,57}$ Thus the local adolescent normative is important for the use of the TPQ.

Given the recent debates pertaining to the factor structure of personality in adults, ${ }^{8-10}$ it is intriguing to examine the relationship between the JEPQ and the TPQ in adolescents. On the basis of correlation between the two scales, each TPQ scale was correlated about equally with two of the three JEPQ scales (if we ignore the correlation with the $\mathrm{L}$ scale). The patterns, e.g., the NS is moderately correlated with the $\mathrm{P}$, and the $\mathrm{HA}$ is correlated positively with the $\mathrm{N}$ and negatively with the $\mathrm{E}$, were consistent with those found in adults. ${ }^{27,31,39}$

Our results of the EFA for all scales of the TPQ and the JEPQ together partly supported the giantthree personality theory ${ }^{9}$ that the best model has three common factors. If $\mathrm{L}$ was not considered and only the highest loading was used for allocation, then there seemed to be a one-to-one correspondence between the TPQ and the JEPQ, i.e., NS versus $P$, HA versus $N$, and RD versus $E$, on the basis of the EFA. However, factors I and II also had loadings from more than two scales. This pattern is consistent with a previous factor analysis of the two scales together in Czech adults. ${ }^{31}$ On the other hand, a twin study in American adults, in which the extent to which the TPQ and the EPQ assess the same versus different dimensions of genetic and environmental variability, has demonstrated that each of the two questionnaires provides incomplete descriptions of the structure of heritable personality differences. ${ }^{38}$ Although the low to moderate intercorrelations between the TPQ and the JEPQ could be attributed to the imprecision in measurement in both scales, the internal consistency and reliability of the two scales reported in these three studies were in comparable ranges. A consistent pattern coming from studies of three different populations indicate that though there is varying degree of construct overlapping between the two questionnaires, the TPQ and the JEPQ are not alternative descriptions of the same construct.

From the practical point of view, the utility of both personality questionnaires can be assessed in terms of their predictability of various behavioral problems. Many studies have shown that behavioral problems in childhood are related to psychiatric disorders in adulthood. ${ }^{58,59}$ Thus, identification of correlates with childhood behavioral problems will be valuable in terms of etiological investigation and early intervention. The pattern of association between personality scales and behavioral problems in this study is consistent with the prediction of their underlying construct. Since the HA of the TPQ and the N of the JEPQ fell on the same factor, both were associated with all the internalizing behavioral problems except Somatic Complaints for the HA. Similarly, the NS of the TPQ and the P of the JEPQ, which fell on the same factor, were associated with all the externalizing behavioral problems. However, a slight difference between the two personality questionnaires is that for each behavioral syndrome, there was only one personality dimension of the TPQ exhibit a significant association, while two personality dimensions of the JEPQ might exhibit a significant association, though in opposite directions. For 
example, the $\mathrm{E}$ and the $\mathrm{N}$ scales were associated with Withdrawn, the E and the P scales with Social Problems, and the $\mathrm{P}$ and the L scales with Delinquent Behavior. Thus, the scales of the TPQ are relatively more specifically associated with behavioral problems than the scales of the JEPQ. A similar advantage of the TPQ over the JEPQ has been found in their relationship with various substance uses, ${ }^{60}$ in which only the NS of the TPQ was associated with substance use, whereas nearly all four scales of the JEPQ were associated with substance use.

Although the TPQ is not completely satisfactory in terms of psychometric properties, this study does support its utility in adolescents, especially the NS and the HA in the study of behavioral problems. In recent studies assessing the associa- tion between the NS and $\mathrm{DRD} 4$ gene, a consistent association exists only when subjects were relatively young (e.g., 18 to 35 years). ${ }^{35,36}$ Investigation among youths has been advocated to further elucidate this issue. For this purpose our results provide empirical support for the applicability of the NS and the HA scales of the TPQ in adolescents.

\section{ACKNOWLEDGMENT}

The authors would like to thank the late Dr. Hans J. Eysenck for granting Dr. Wei J. Chen permission to translate the JEPQ into Chinese, Dr. C.R. Cloninger for granting Dr. Suo-Jeng Wang permission to translate the TPQ into Chinese, and Dr. Tom Przybeck for providing us with the scoring keys of the TPQ. The authors also thank the principals and teachers of the participating schools for their help in recruiting students.

\section{REFERENCES}

1. Friedman HS. Long-term relations of personality and health: dynamisms, mechanisms, tropisms. J Pers 2000;68: 1089-1107.

2. Heath AC, Eaves LJ, Martin NG. The genetic structure of personality III. Multivariate genetic item analysis of the EPQ scales. Pers Individ Differ 1989;10:877-888.

3. Lake RI, Eaves LJ, Maes HH, Heath AC, Martin NG. Further evidence against the environmental transmission of individual differences in neuroticism from a collaborative study of 45,850 twins and relatives on two continents. Behav Genet 2000;30:223-33.

4. Martin N, Goodwin G, Fairburn C, Wilson R, Allison D, Cardon LR, et al. A population-based study of personality in 34,000 sib-pairs. Twin Res 2000;3:310-315.

5. Eaves L, Rutter M, Silberg JL, Shillady L, Maes H, Pickles A. Genetic and environmental causes of covariation in interview assessments of disruptive behavior in child and adolescent twins. Behav Genet 2000;30:321-333.

6. Barrett P, Eysenck S. The assessment of personality factors across 25 countries. Pers Individ Differ 1984;5:615-632.

7. Barrett PT, Petrides KV, Eysenck SBG, Eysenck HJ. The Eyesenck Personality Questionaire: an examination of the factorial similarity of $\mathrm{P}, \mathrm{E}, \mathrm{N}$, and $\mathrm{L}$ across 34 countries. Pers Individ Differ 1998;25:805-819.

8. Barrett P. Rejoinder to: The Eysenckian personality structure: a giant three or big five model in Hong Kong? Pers Individ Differ 1999;26:175-186.

9. Ng HS, Cooper M, Chandler P. The Eysenckian personality structure: a giant three or big five model in Hong Kong? Pers Individ Differ 1998;25:1111-1131.

10. Zuckerman M, Kuhlman DM, Joireman J, Teta P, Kraft M. A comparison of three structural models for personality: the big three, the big five, and the alternative five. J Pers Soc Psychol 1993;65:757-768.

11. Eysenck HJ. Manual of the Eysenck Personality Questionnaire. San Diego, CA: Digits, 1975.

12. Caruso JC, Edwards S. Reliability generalization of the
Junior Eysenck Personality Questionnaire. Pers Individ Differ 2001;31:173-184.

13. del Barrio V, Moreno-Rosset C, Lopez-Martinez R, Olmedo M. Anxiety, depression and personality structure. Pers Individ Differ 1997;23:327-335.

14. Eysenck SB, Long FY. A cross-cultural comparison of personality in adults and children: Singapore and England. J Pers Soc Psychol 1986;50:124-130.

15. Wilson D, Mundy-Casle AC, Greenspan R. Reiability and factorial validity of the Junior Eysenck Personality Questionnaire in Zimbabwe. Int J Psychol 1988;23:637-646.

16. Brayne C, Do K-A, Green L, Green AC. Is health protective behaviour in adolescents related to personality? A study of sun protective behaviour and the Eysenck Personality Questionnaire (junior version) in Queensland. Pers Individ Differ 1998;25:889-895.

17. Francis LJ. The relationship between Eysenck's personality factors and attitude towards substance use among 13-15year olds. Pers Individ Differ 1996;21:633-640.

18. Hopper JL, White VM, Macaskill GT, Hill DJ, Clifford CA. Alcohol use, smoking habits and the Junior Eysenck Personality Questionnaire in adolescent Australian twins. Acta Genet Med Gemellol 1992;41:311-324.

19. Fisher BE. Junior Eysenck Personality Questionnaire: neuroticism, depressive symptoms and sleep disturbance in elementary-school age children. Pers Individ Differ 1993;15: 233-235.

20. Jones SH, Francis LJ. The relationship between Eysenck personality-factors and attitude towards truancy among 13-15 year olds in England and Wales. Pers Individ Differ 1995;19: 225-233.

21. Mynard H, Joseph S. Bully/victim problems and their association with Eysenck's personality dimensions in 8 to 13 year-olds. Br J Educ Psychol 1997;67:51-54.

22. Tranah T, Harnett P, Yule W. Conduct disorder and personality. Pers Individ Differ 1998;24:741-745.

23. Cloninger CR. A systematic method for clinical descrip- 
tion and classification of personality variants. Arch Gen Psychiatry 1987;44:573-588.

24. Mulder RT, Joyce PR. Temperament and the structure of personality disorder symptoms. Psychol Med 1997;27:99-106.

25. Mulder RT, Joyce PR. Relationships of the Tridimensional Personality Questionnaire to mood and personality measures for depressed patients. Psychol Rep 1994;75:1315-1325.

26. Pomerleau CS, Pomerleau OF, Flessland KA, Basson SM. Relationship of Tridimensional Personality Questionnaire scores and smoking variables in female and male smokers. J Subst Abuse 1992;4:143-154.

27. Sher KJ, Bartholow BD, Wood MD. Personality and substance use disorders: a prospective study. J Consult Clin Psychol 2000;68:818-829.

28. Wills TA, Vaccaro D, McNamara G. Novelty seeking, risk taking, and related constructs as predictors of adolescent substance use: an application of Cloninger's theory. J Subst Abuse 1994;6:1-20.

29. Bagby RM, Parker JDA, Joffe RT. Notes and shorter communications: confirmatory factor analysis of the Tridimensional Personality Questionnaire. Pers Individ Differ 1992;13:1245-1246.

30. Cloninger CR, Przbeck TR, Svrakic DM. The Tridimensional Personality Questionnaire: U.S. normative data. Psychol Rep 1991;69:1047-1057.

31. Kozeny J, Kubicka L, Prochazkova Z. Psychometric properties of the Czech version of Cloninger's three dimensional personality questionnaire. Pers Individ Differ 1989;10: 1253-1259.

32. Nixon SJ, Parsons OA. Cloninger's tridimensional theory of personality: construct validity in a sample of college students. Pers Individ Differ 1989;12:1261-1267.

33. Giancola PR, Zeichner A, Newbolt WH. Construct validity of the dimensions of Cloninger's Tridimensional Personality Questionnaire. Pers Individ Differ 1994;5:627-636.

34. Otter C, Huber J. Cloninger's Tridimensional Personality Questionnaire: reliablity in an English sample. Pers Individ Differ 1995;18:471-480.

35. Ebstein RP, Belmaker RH. Saga of an adventure gene: Novelty seeking, substance abuse and the dopamine D4 receptor (D4DR) exon III repeat polymorphism. Mol Psychiatry 1997;2:381-384.

36. Lusher JM, Chandler C, Ball D. Dopamine D4 receptor gene (DRD4) is associated with Novelty Seeking (NS) and substance abuse: the saga continues. Mol Psychiatry 2001;6: 497-499.

37. Sigvardsson S, Bohman M, Cloninger CR. Structure and stability of childhood personality: prediction of later social adjustment. J Child Psychol Psychiatry 1987;28:929-946.

38. Heath AC, Cloninger CR, Martin NG. Testing a model for the genetic structure of personality: a comparison of the personality systems of Cloninger and Eysenck. J Pers Soc Psychol 1994;66:762-775.

39. Zuckerman M, Cloninger CR. Relationships between Cloninger's, Zuckerman's, and Eysenck's dimensions of personality. Pers Individ Differ 1996;21:283-285.

40. Eaves LJ, Eysenck HJ, Martin NG. Genes, Culture and Personality: An Empirical Approach. London, UK: Academic Press, 1989.

41. Belter RW, Foster KY, Imm PS. Convergent validity of select scales of the MMPI and the Achenbach Child Behavior Checklist-Youth Self-report. Psychol Rep 1996;79:1091-1100.
42. Gedeon SW, Schuerger JM. Introducing a new adolescent psychopathology screen: the High School Personality Questionnaire pathology section. Psychol Rep 1998;83:1257-1258.

43. Lin $\mathrm{CCH}$, Chen WJ, Yang HJ, Hsiao CK, Tien AY. Performance on the Wisconsin Card Sorting Test among adolescents in Taiwan: norms, factorial structure, and relation to schizotypy. J Clin Exp Neuropsychol 2000;22:69-79.

44. Yang HJ, Soong WT, Chiang CN, Chen WJ. Competence and behavioral/emotional problems among Taiwanese adolescents as reported by parents and teachers. J Am Acad Child Adolesc Psychiatry 2000;39:232-239.

45. Eysenck SBG, White O, Eysenck HJ. Personality and mental illness. Psychol Rep 1976;39:1011-1022.

46. Lodhi PH, Thakur S. Personality of drug addicts: Eysenckian analysis. Pers Individ Differ 1993;15:121-128.

47. Chen WJ, Chen HM, Chen CC, Chen CC, Yu WY, Cheng ATA. Cloninger's Tridimensional Personality Questionnaire: psychometric properties and construct validity in Taiwanese adults. Compr Psych 2002;43:158-166.

48. Achenbach TM. Manual for the Child Behavior Checklist/4-18 and 1991 Profile. Burlington, VT: University of Vermont Department of Psychiatry, 1991.

49. Cole DA. Utility of confirmatory factor analysis in test validation research. J Consult Clin Psychol 1987;55:584-594.

50. SAS Institute Inc. SAS/STAT Software: Changes and Enhancement Through 6.12. Cary, NC, SAS Institute Inc, 1997.

51. Fleiss JL. The Design and Analysis of Clinical Experiments. New York, NY: Wiley, 1986.

52. Cloninger CR, Svrakic DM, Przybeck TR. A psychobiological model of temperament and character. Arch Gen Psychiatry 1993;50:975-990.

53. Wilson D, Panditji L. Cross-cultural cross-validation of the Junior Eysenck Personality Questionnaire among Zimbabwean school children. Psychol Rep 1991;69:261-262.

54. Svrakic DM, Przybeck TR, Cloninger CR. Further contribution to conceptual validity of the unified biosocial model of personality: US and Yugoslav data. Compr Psychiatry 1991;32: 195-209.

55. Giaconia RM, Reinherz HZ, Silverman AB, Pakiz B, Frost AK, Cohen E. Ages of onset of psychiatric disorders in a community population of older adolescents. J Am Acad Child Adolesc Psychiatry 1994;33:706-717.

56. Krebs H, Weyers P, Janke W. Validation of the German version of Cloninger's TPQ: replication and correlations with stress coping, mood measures and drug use. Pers Individ Differ 1998:21:283-285.

57. Weyers P, Krebs H, Janke W. Reliability and construct validity of the German version of Cloninger's Tridimensional Personality Questionnaire. Pers Individ Differ 1995;19:853-861.

58. Hofstra MB, Van der Ende J, Verhulst FC. Adolescents' self-reported problems as predictors of psychopathology in adulthood: 10-year follow-up study. Br J Psychiatry 2001;179: 203-209.

59. Hofstra MB, Van der Ende J, Verhulst FC. Child and adolescent problems predict DSM-IV disorders in adulthood: a 14-year follow-up of a Dutch epidemiological sample. J Am Acad Child Adolesc Psychiatry 2002;41:182-189.

60. Kuo PH, Yang HJ, Soong WT, Chen WJ. Substance use among adolescents in Taiwan: associated personality traits, incompetence, and behavioral/emotional problems. Drug Alcohol Depend 2002;67:27-39. 